\title{
Trends in Exposure to Chemicals in Personal Care and Consumer Products
}

\author{
Antonia M. Calafat ${ }^{1} \cdot$ Liza Valentin-Blasini ${ }^{2} \cdot{\text { Xiaoyun } \mathrm{Ye}^{3}}^{3}$
}

Published online: 5 September 2015

(C) Springer International Publishing AG (outside the USA) 2015

\begin{abstract}
Synthetic organic chemicals can be used in personal care and consumer products. Data on potential human health effects of these chemicals are limited — sometimes even contradictory - but because several of these chemicals are toxic in experimental animals, alternative compounds are entering consumer markets. Nevertheless, limited information exists on consequent exposure trends to both the original chemicals and their replacements. Biomonitoring (measuring concentrations of chemicals or their metabolites in people) provides invaluable information for exposure assessment. We use phthalates and bisphenol A-known industrial chemicals - and organophosphate insecticides as case studies to show exposure trends to these chemicals and their replacements (e.g., other phthalates, non-phthalate plasticizers, various bisphenols, pyrethroid insecticides) among the US general population. We compare US trends to national trends from Canada and Germany. Exposure to the original compounds is still prevalent among these general populations, but exposures to alternative chemicals may be increasing.
\end{abstract}

This article is part of the Topical Collection on Synthetic Chemicals and Health

Antonia M. Calafat

aic7@cdc.gov

Liza Valentin-Blasini

lbv5@cdc.gov

Xiaoyun Ye

xay5@cdc.gov

1 Centers for Disease Control and Prevention, 4770 Buford Hwy, MS F17, Atlanta, GA 30341, USA

2 Centers for Disease Control and Prevention, 4770 Buford Hwy, MS F19, Atlanta, GA 30341, USA

3 Centers for Disease Control and Prevention, 4770 Buford Hwy, MS F53, Atlanta, GA 30341, USA
Keywords Biomonitoring $\cdot$ Bisphenol $\cdot$ DINCH $\cdot$ Endocrine disruptors $\cdot$ Exposure $\cdot$ Insecticides $\cdot$ Pesticides $\cdot$ Phthalates

\section{Introduction}

People in our modern world are exposed to a wide range of man-made environmental chemicals, and animal studies suggest the potential for harmful effects to human health for many of these compounds $[1 \bullet]$. Some of these synthetic organic chemicals can be used in personal care and consumer products both as "active" (e.g., organophosphate insecticides) or "inactive" (e.g., phthalates, bisphenol A [BPA]) ingredients.

Many of these compounds are endocrine disruptors in animal studies, and evidence also is mounting on their potential effects on human health [2-4]. Therefore, given the scientific community and public's concern over toxicity of these compounds, national, state, and local government entities in the USA and across the world have banned the use of some of these chemicals in a variety of products. Furthermore, environmental and public health organizations have advocated for the removal of certain chemicals from commerce. As a result, other chemicals might be entering the market and exposure to the original and the alternative compounds will change.

Understanding the extent of exposure to all of these environmental chemicals is of public health relevance. For exposure assessment, biomonitoring or measuring the concentrations of chemicals or their breakdown by-products in people is a useful tool $[5,6]$. In this short review, we will present several case studies (phthalates, BPA, organophosphate insecticides) to highlight the usefulness of nationwide biomonitoring programs to track exposure trends to these compounds and their replacements since the early 2000s, particularly in the USA. If 
available, we will also compare the US data to data from other countries.

\section{Examples of Population-Based Biomonitoring Surveys}

Changes in reformulation of products and legislation may have implications for chemical exposures and potential human health risks. While substitute chemicals enter consumer markets, limited information exists on consequent trends in exposures to both the original and their corresponding replacements. Population-based biomonitoring programs or strategies could be useful to assess such trends. For this review, we will focus on two North American programs, the US National Health and Nutrition Examination Survey (NHANES) and the Canadian Health Measures Survey (CHMS), and two programs in Europe, the German Environmental Survey (GerES) and the German Environmental Specimen Bank (ESB).

In the USA, every year since 1999, NHANES, administered by the Centers for Disease Control and Prevention (CDC), recruits approximately 5000 participants who are representative of the US population [7]. NHANES participants undergo a physical examination and provide a detailed medical history. Furthermore, all NHANES participants 1 year of age and older provide blood; participants 6 years of age and older also provide one spot urine sample [8]. Some of the NHANES biological specimens are used to provide the most comprehensive assessment of the US general population's exposure to select environmental chemicals [9, 10]. Furthermore, biomonitoring NHANES data have been used to track exposure trends to several environmental chemicals, including heavy metals, phthalates, dichlorophenols, cotinine, pesticides, and polyfluoroalkyl substances [11, 12, 13•, 14-20].

Similar to NHANES in the USA, the German Federal Environment Agency conducts GerES (http://www. umweltbundesamt.de/en/topics/health/assessingenvironmentally-related-health-risks/german-environmentalsurvey-geres), a nationwide population-representative study with the aim of evaluating exposures to environmental chemicals and their sources [21]. Since its inception in 1985 and until 1999, the first three GerES included only adults, GerES IV (2003-6) only children 3-14 years of age, and the ongoing GerES V (2014-7) will only sample children and adolescents (3-17 years). In addition, each year since 1985, ESB, also administered by the German Federal Environment Agency [21], collects and stores blood and one 24-h urine sample from approximately 120 students (20-29 years old) residing at four university cities throughout Germany (Munster, Greifswald, Halle/Saale, Ulm). ESB and GerES biological samples have been used to investigate exposures to select environmental chemicals including bisphenol A (BPA) and phthalates [22-26, 27•, 28, 29].

CHMS, administered by Health Canada, is designed to provide representative data at the national level, and, since 2007, also includes a biomonitoring component. CHMS participants 6-79 years of age (3-79 since 2009 [30]) undergo a physical examination and provide questionnaire data and biospecimens [31]. Some of the CHMS biological samples are used to investigate exposures to select environmental chemicals including BPA, phthalates, and organophosphate and pyrethroid insecticides among Canadian children and adults [30].

NHANES, GerES, ESB, and CHMS have provided critical data to track temporal trends of exposure to phthalates, BPA, organophosphate, and pyrethroid insecticides and some of their replacements $[13 \cdot, 19,20,22-25,27 \cdot, 28-30]$.

\section{Plasticizers: Phthalates and Phthalate Replacements}

Phthalates have been widely used for decades in consumer goods and in personal care products [32]. High-molecularweight phthalates (e.g., di-2-ethylhexyl phthalate [DEHP]) are primarily used as plasticizers of polyvinyl chloride (PVC), which, in turn, is used in numerous consumer products, flooring and wall coverings, toys, food contact applications, and medical instruments [33, 34]. Low-molecularweight phthalates, such as di- $n$-butyl phthalate (DnBP), are used as solvents and plasticizers for cellulose acetate to make lacquers, varnishes, medication coatings, perfume, cosmetics, and other personal care products [35-42, 43•].

Exposure to phthalates in the developed world is pretty much universal [10, 22, 30, 44-50]. However, at high doses, exposure to several phthalates has been associated with a spectrum of male reproductive system disorders in animals [51-53]. On the other hand, evidence exists, albeit at times equivocal or contradictory, that environmental exposures to phthalates may also adversely affect human health [51, 53-58].

Because of widespread exposure and the potential of phthalates to negatively impact health, the European Union banned the use of certain phthalates in toys and childcare articles starting in 2001 [59] and Canada restricted the allowable concentrations of several phthalates in the soft vinyl of toys and child care articles in 2012 [60]. Similarly, in 2008, in the USA, the Consumer Product Safety Improvement Act banned the use of three phthalates (DnBP, butylbenzyl phthalate (BBzP), DEHP) in any amount $>0.1 \%$ in child care articles and placed an interim restriction on three other phthalates (di-isononyl phthalate (DiNP), di-isodecyl phthalate (DiDP), di-n-octyl phthalate (DnOP)) in toys that can be put in a child's mouth [61]. Subsequently, in 2014, the US federal government proposed to lift the interim prohibition for DnOP 
and DiDP, but to permanently ban DiNP, and four additional compounds diisobutyl phthalate (DiBP), di- $n$-pentyl phthalate, di- $n$-hexyl phthalate, and dicyclohexyl phthalate at levels $>0.1 \%$ in any children's toy or child care article [62].

In addition to the legislative activity, several environmental and public health organizations have sought to reduce phthalate exposures by advocating for the removal of phthalates from personal care products and the use of potentially safer alternatives [63]. Furthermore, in the USA, in response to public concerns and consumers' demands (e.g., Campaign for Safe Cosmetics), Revlon and other major companies phased out phthalates used in nail polish and from their consumer product raw materials, finished products, and components, and many other cosmetic companies also pledged to eliminate phthalates from their products [64•].

Biomonitoring data may provide useful insights into these ongoing market changes. For example, DEHP, historically the most common PVC phthalate plasticizer, is being replaced with other phthalates (e.g., DiNP, DiDP) or non-phthalate plasticizers (e.g., di(isononyl)cyclohexane-1,2-dicarboxylate $\left(\mathrm{DINCH}^{\circledR}\right)$ ). DINCH ${ }^{\circledR}$ was introduced commercially in 2002 as a substitute for phthalate plasticizers in many PVC products particularly in sensitive application areas such as toys, medical devices, and food packaging. Of interest, metabolites of DINCH were not detected in urine specimens collected from German and US adults before $2002[27 \bullet, 65 \bullet]$. By contrast, the $\mathrm{DINCH}^{\circledR}$ metabolite cyclohexane-1,2-dicarboxylic acidmono(hydroxy-isononyl) ester (MHNCH) was detected in $19.3 \%$ of NHANES 2011-2012 participants' urine (range $\geq 0.4-168.1 \mu \mathrm{g} / \mathrm{L}$ ) [10]. Similarly, in 2012, MHNCH was detected in the urine of $98 \%$ of German ESB student samples (range $\geq 0.05-236 \mu \mathrm{g} / \mathrm{L}$ ) [27•]. These data suggest that the general public in the USA and Germany is currently exposed to the non-phthalate plasticizer DINCH.

In a recent report using NHANES 2001-2010 data, Zota et al. showed that concentrations of the metabolites of DEHP peaked in $2005-2006$ and declined $50 \%$ by $2009-2010$ while the concentrations of the metabolites of two of the potential DEHP phthalate replacements, namely DiNP and DiDP, increased 2.6 and 1.1 times, respectively [13•]. Similarly, Wittasek et al., using German ESB samples collected between 1988 and 2003, reported that median DEHP intakes, estimated from the DEHP metabolite concentrations, remained essentially unchanged $(\sim 4 \mu \mathrm{g} / \mathrm{kg} /$ day $)$ between 1988 and 1993 but, since 1996, followed a downward trend to $2.4 \mu \mathrm{g} / \mathrm{kg} /$ day in 2003 [28]. By contrast, daily DiNP median intakes doubled from $1998(0.20 \mu \mathrm{g} / \mathrm{kg} /$ day $)$ to $2003(0.40 \mu \mathrm{g} / \mathrm{kg} /$ day); Wittasek et al. did not assess exposure to DiDP [28]. Although CHMS data exist only for 2007-2011 and CHMS measured fewer phthalate metabolites than NHANES during that time period, the 2007-2009 and 2009-2011 CHMS geometric mean concentrations of mono(2-ethyl-5hydroxyhexyl) phthalate and mono(2-ethyl-5-oxohexyl) phthalate, the two DEHP oxidative metabolites evaluated by both surveys, are remarkably similar to those reported by NHANES in 2007-2008 and 2009-2010, respectively (Fig. 1) $[10,30]$. These data suggest that exposure to DEHP in the USA, Canada, and Germany may be decreasing, while exposure to DiNP, at least in the USA and Germany, where data exist, appears to be on the rise.

In addition to changes in exposure to high-molecularweight phthalates, exposure to low-molecular-weight phthalates may also be changing. In the USA, during 20012010 , the concentrations of the metabolites of BBzP, DnBP, and diethyl phthalate (DEP) declined $20-50 \%$, depending of the phthalate, while concentrations of the DiBP metabolite increased threefold [13•]. Wittasek et al. reported similar trends in Germany for the years 1988-2003 [28]. For example, the median daily intake of DnBP in $2003(1.9 \mu \mathrm{g} / \mathrm{kg} /$ day $)$ was considerably lower than between 1988 and $1993(\sim 7 \mu \mathrm{g} /$ $\mathrm{kg} /$ day); for DiBP, a potential replacement of DnBP, median intakes increased slightly between $1988(1.1 \mu \mathrm{g} / \mathrm{kg} /$ day $)$ and $2003(1.4 \mu \mathrm{g} / \mathrm{kg} / \mathrm{day})$ [28]. GerES IV biomonitoring data also suggest a decrease in median (95th percentile) urinary concentrations (in $\mu \mathrm{g} / \mathrm{L}$ ) of mono- $n$-butyl phthalate (MBP) (166 (624) vs 100 (364), respectively) for the 2001-2 GerES IV pilot (254 children 3-14 years) and the 2003-6 GerES IV (137 3-5 year olds); mono-isobutyl phthalate, the DiBP metabolite, was only measured in GerES IV [22, 24]. This apparent decline may be related, at least in part, to the fact that DnBP, the parent compound of MBP, was one of the first phthalates being restricted in all toys, childcare articles, and cosmetics in 2001 in the European Union [66]. Nonetheless, legislation is not the only factor affecting market trends. For instance, DEP is not regulated in the USA or in Canada; yet, NHANES data show a clear downward trend in exposure to DEP for all segments of the population [13•]; CHMS also suggests a decline in concentrations of monoethyl phthalate, the main DEP metabolite from 2007 to 2011 (Fig. 1) [30].

Taken together, these trends suggest that exposures to phthalates and their replacements may be affected by changes in production and use of these compounds in the consumer marketplace prompted, at least in part, from the combined efforts of legislators, advocacy groups, industry, and the general public $[13 \cdot, 27,28,64]$.

\section{Industrial Chemicals: BPA}

BPA, one of the most studied synthetic chemicals in the past decades, is primarily used to manufacture polycarbonate plastic and epoxy resins and in the processing of PVC plastic and of thermal paper [67, 68].

Like for phthalates, exposure to BPA in the developed world is widespread [10, 25, 69-77]. Data from NHANES III, conducted from 1988 through 1994, first demonstrated 


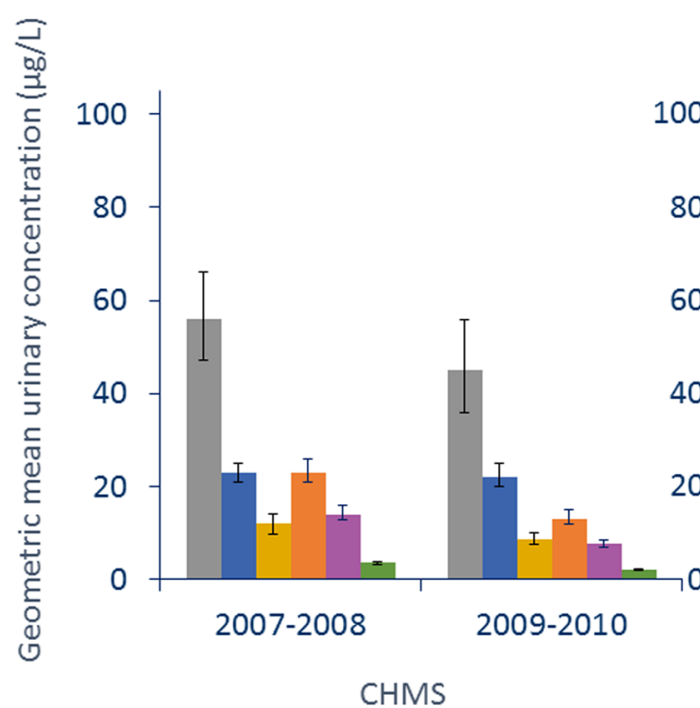

Fig. 1 Geometric mean urinary concentrations (in $\mu \mathrm{g} / \mathrm{L}$ ) of select phthalate metabolites measured in 2007-2008 and 2009-2010 as part of both the US National Health and Nutrition Examination Survey

exposure to BPA among US adults [78]. Subsequently, yearly NHANES data suggest that the majority of Americans have continued to be exposed to BPA since 2003-2004 when BPA became part of the NHANES ongoing biomonitoring program [10]. Of interest, from NHANES 2003-2004 to NHANES 2011-2012, geometric mean concentrations of BPA have decreased from $2.64 \mu \mathrm{g} / \mathrm{L}(2.58 \mu \mathrm{g} / \mathrm{g}$ creatinine $)$ to $1.51 \mu \mathrm{g} / \mathrm{L}$ $(1.72 \mu \mathrm{g} / \mathrm{g}$ creatinine) [10]. By contrast, the CHMS geometric mean urinary concentration of BPA in 2007-2009 and 20092011 did not change $(1.2 \mu \mathrm{g} / \mathrm{L})$ [30]. Similarly, using German ESB urine samples collected between 1995 and 2009 from University of Muenster students, Koch et al. reported that median BPA intakes had remained essentially unchanged (from $0.043 \mu \mathrm{g} / \mathrm{kg} /$ day in 1995 to $0.039 \mu \mathrm{g} / \mathrm{kg} /$ day in 2009) [25]. These data suggest a downward trend in exposure to BPA in the USA, but not in Germany or Canada. The reasons for the different trends are not clearly evident, although differences in calendar years surveyed, sampling strategies, and analytical methodologies may play a role. Future data will provide useful information to evaluate whether exposure to BPA continues to decline in the USA and whether the marketing of BPA-free products and bans enacted since the late 2000s in Europe and Canada may contribute to a decline in exposures to BPA also in Germany and Canada.

Government agencies in North America and the European Union [79-81], among others, have restricted the use of BPA in certain products because in animal studies, BPA can have reproductive and developmental effects [68]. Following such restrictions and the public pressure prompted from concerns regarding the toxicity of BPA and its potential adverse implications for human health, the use of BPA alternatives (e.g., other bisphenols, non-bisphenol products) may increase [68, 82-84]. However, information on the extent of exposure to
BPA alternatives is rather limited. Only one study so far has quantified concurrently BPA and three bisphenol analogs, bisphenol S (BPS, 4,4'-sulfonyldiphenol), bisphenol F (BPF, 4,4'-dihydroxydiphenylmethane), and bisphenol AF (BPAF, hexafluorobisphenol A), in samples collected between 2009 and 2012 from 100 US adults [85]. The highest frequency of detection and median concentrations were for BPA (95\%, $0.72 \mu \mathrm{g} / \mathrm{L})$, followed by BPS (78 \%, $0.13 \mu \mathrm{g} / \mathrm{L})$, and BPF $(55 \%, 0.08 \mu \mathrm{g} / \mathrm{L})$; BPAF was detected infrequently $(\sim 10 \%$ of samples). These limited data suggest that US adults are exposed both to BPA and several bisphenol analogs. Future biomonitoring datasets using representative samples will be invaluable to track potential changes in human exposure to the alternative bisphenols from shifts in commercial formulations, public awareness, and regulations.

\section{Pesticides: Organophosphate and Pyrethroid Insecticides}

In the most recent market estimates of pesticide sales and use, insecticides were the second most common pesticide type, after herbicides, used in the USA in 2006-2007, and organophosphates constituted a significant portion of the insecticides used in US commercial and residential settings [86]. Nonetheless, of all insecticides used in the USA, the use of organophosphate insecticides has declined to $35 \%$ in 2007 from $72 \%$ in 2000 . However, chlorpyrifos was the most commonly used organophosphate insecticide in 2007 despite the phasing out of chlorpyrifos from most home-including outdooruses and some agricultural applications in the early 2000s [87]. As a result, use of pyrethroids, labeled as less toxic than 
organophosphates, for commercial and household residential applications has increased [88].

In population surveys, exposure to chlorpyrifos or chlorpyrifos-methyl has been generally assessed from the urinary concentrations of the specific metabolite 3,5,6-trichloro2-pyridinol (TCPy), while 3-phenoxybenzoic acid (3-PBA), a non-specific metabolite of several pyrethroids, has been used as a biomarker of exposure to pyrethroid insecticides $[19,20$, 30, 89]. Urinary concentrations of 3-PBA from GerES IV suggest that German children are exposed to synthetic pyrethroids $[19,20,30,89]$. The lack of other survey data precludes the evaluation of trends of exposure to pyrethroids in Germany. By contrast, CHMS and NHANES data can be used to assess exposure trends to these insecticides in North America. For example, the median 3-PBA concentrations in CHMS participants 6-79 years of age increased from $0.22 \mu \mathrm{g} / \mathrm{L}$ $(0.26 \mu \mathrm{g} / \mathrm{g}$ creatinine $)$ in $2007-2009$ to $0.36 \mu \mathrm{g} / \mathrm{L}(0.33 \mu \mathrm{g} / \mathrm{g}$ creatinine) in 2009-2011; CHMS does not include TCPy [30]. In NHANES, 3-PBA median concentrations have increased by $60 \%$ from $0.25 \mu \mathrm{g} / \mathrm{L}$ in $1999-2000$ to $0.40 \mu \mathrm{g} / \mathrm{L}$ in 2009 2010 [10]. Interestingly, the NHANES median concentrations of TCPy decreased by $39 \%(1.70 \mathrm{vs} 1.03 \mu \mathrm{g} / \mathrm{L})$ during the same time period [10]. These results suggest a downward trend in exposure to chlorpyrifos and a parallel upward trend in exposure to its alternatives, synthetic pyrethroids, in the USA since the early 2000s. Although no data exist to track exposures to chlorpyrifos in Canada, based on CHMS biomonitoring data, exposure to synthetic pyrethroids seems to be on the rise.

\section{Conclusion}

The development and use of synthetic chemicals grew exponentially in the twentieth century to improve society's quality of life. These changes brought a parallel widespread exposure to many of these chemicals used in personal care and consumer products among all segments of the population in the USA and throughout the world. Because of the known animal toxicity of many of these chemicals (e.g., phthalates, BPA, organophosphate insecticides), increased public concerns, and government regulations, alternative chemicals are entering consumer markets. As a result, exposure to chemicals used in personal care and consumer products has changed in the past two decades. Understanding the extent of exposure to these chemicals is of public health relevance, and biomonitoring (i.e., measuring the concentrations of chemicals or their breakdown byproducts in people) has been increasingly used as a tool for exposure assessment. Of interest, biomonitoring data also provide invaluable information to track exposure trends and show that although exposure to the original personal care and consumer products chemicals is still prevalent among the general population, exposures to the alternative chemicals (e.g., non-phthalate plasticizers, other bisphenols, pyrethroid insecticides) appear to be on the rise, at least in the USA, Germany, and Canada.

Acknowledgments We thank the researchers at the National Center for Health Statistics (NCHS) and National Center for Environmental Health (NCEH) for their dedication throughout the years to the success of NHANES.

Disclaimer The findings and conclusions in this report are those of the authors and do not necessarily represent the official position of the Centers for Disease Control and Prevention (CDC). Use of trade names is for identification only and does not imply endorsement by the Centers for Disease Control and Prevention, the Public Health Service, or the US Department of Health and Human Services.

\section{Compliance with Ethics Guidelines}

Conflict of Interest Antonia M. Calafat, Liza Valentin-Blasini, and Xiaoyun Ye declare that they have no conflict of interest.

Human and Animal Rights and Informed Consent This article does not contain any studies with human or animal subjects performed by any of the authors.

\section{References}

Papers of particular interest, published recently, have been highlighted as:

- Of importance

1. Bergman A, Heindel JJ, Kasten T, Kidd KA, Jobling S, Neira M, et al. The impact of endocrine disruption: a consensus statement on the state of the science. Environ Health Perspect. 2013;121:A1046 . The paper summarizes the scientific information on human and wildlife impacts of endocrine disruption and lists key concerns for decision makers and others to improve human and wildlife health by preventing environmentally induced diseases.

2. Casals-Casas C, Desvergne B. Endocrine disruptors: from endocrine to metabolic disruption. Annu Rev Physiol. 2011;73:135-62.

3. Frye CA, Bo E, Calamandrei G, Calza L, Dessi-Fulgheri F, Fernandez M, et al. Endocrine disrupters: a review of some sources, effects, and mechanisms of actions on behaviour and neuroendocrine systems. J Neuroendocrinol. 2012;24:144-59.

4. Schug TT, Janesick A, Blumberg B, Heindel JJ. Endocrine disrupting chemicals and disease susceptibility. J Steroid Biochem Mol Biol. 2011;127:204-15.

5. Angerer J, Bird MG, Burke TA, Doerrer NG, Needham L, Robison $\mathrm{SH}$, et al. Strategic biomonitoring initiatives: moving the science forward. Toxicol Sci. 2006;93:3-10.

6. Human Biomonitoring for Environmental Chemicals. 2006. The National Academies Press.

7. CDC. National Health and Nutrition Examination Survey. National Center for Health Statistics. 2015. Available: http://www.cdc.gov/ nchs/nhanes.htm [accessed $201511 \mathrm{Mar}$. 
8. Calafat AM. The U.S. National Health and Nutrition Examination Survey and human exposure to environmental chemicals. Int J Hyg Environ Health. 2012;215:99-101.

9. CDC. NHANES Environmental Chemical Data Tutorial. National Center for Health Statistics. 2011. Available: http://www.cdc.gov/ nchs/tutorials/environmental/index.htm [accessed $20151 \mathrm{Mar}$.

10. CDC. Fourth National Report on Human Exposure to Environmental Chemicals. Updated Tables, February 2015. Atlanta, GA: Centers for Disease Control and Prevention; National Center for Environmental Health; Division of Laboratory Sciences. 2015. Available: http://www.cdc.gov/ biomonitoring/pdf/FourthReport_UpdatedTables_Feb2015.pdf [accessed $201520 \mathrm{Apr}$.

11. Jones RL, Homa DM, Meyer PA, Brody DJ, Caldwell KL, Pirkle $\mathrm{JL}$, et al. Trends in blood lead levels and blood lead testing among US children aged 1 to 5 years, 1988-2004. Pediatrics. 2009;123: e376-85.

12. Ye XY, Wong LY, Zhou XL, Calafat AM. Urinary concentrations of 2,4-dichlorophenol and 2,5-dichlorophenol in the US population (National Health and Nutrition Examination Survey, 2003-2010): trends and predictors. Environ Health Perspect. 2014;122:351-5.

13. Zota AR, Calafat AM, Woodruff TJ. Temporal trends in phthalate exposures: findings from the National Health and Nutrition Examination Survey, 2001-2010. Environ Health Perspect. 2014;122:235-41. First report to examine changes in phthalate exposure over 10 years using a large representative sample of the U.S. population.

14. Birch RJ, Bigler J, Rogers JW, Zhuang Y, Clickner RP. Trends in blood mercury concentrations and fish consumption among U.S. women of reproductive age, NHANES, 1999-2010. Environ Res. 2014;133:431-8.

15. Richter PA, Bishop EE, Wang J, Kaufmann R. Trends in tobacco smoke exposure and blood lead levels among youths and adults in the United States: the National Health and Nutrition Examination Survey, 1999-2008. Prev Chronic Dis. 2013;10, E213.

16. Tellez-Plaza M, Navas-Acien A, Caldwell KL, Menke A, Muntner P, Guallar E. Reduction in cadmium exposure in the United States population, 1988-2008: the contribution of declining smoking rates. Environ Health Perspect. 2012;120:204-9.

17. Pirkle JL, Bernert JT, Caudill SP, Sosnoff CS, Pechacek TF. Trends in the exposure of nonsmokers in the U.S. population to secondhand smoke: 1988-2002. Environ Health Perspect. 2006;114:8538 .

18. Kato K, Wong LY, Jia LT, Kuklenyik Z, Calafat AM. Trends in exposure to polyfluoroalkyl chemicals in the US population: 1999-2008. Environ Sci Technol. 2011;45:8037-45.

19. Barr DB, Olsson AO, Wong LY, Udunka S, Baker SE, Whitehead $\mathrm{RD}$, et al. Urinary concentrations of metabolites of pyrethroid insecticides in the general US population: National Health and Nutrition Examination Survey 1999-2002. Environ Health Perspect. 2010;118:742-8.

20. Barr DB, Wong LY, Bravo R, Weerasekera G, Odetokun M, Restrepo P, et al. Urinary concentrations of dialkylphosphate metabolites of organophosphorus pesticides: National Health and Nutrition Examination Survey 1999-2004. Int J Environ Res Public Health. 2011;8:3063-98.

21. Kolossa-Gehring M, Becker K, Conrad A, Schroter-Kermani C, Schulz C, Seiwert M. Environmental surveys, specimen bank and health related environmental monitoring in Germany. Int J Hyg Environ Health. 2012;215:120-6.

22. Becker K, Goen T, Seiwert M, Conrad A, Pick-Fuss H, Muller J, et al. GerES IV: phthalate metabolites and bisphenol A in urine of German children. Int J Hyg Environ Health. 2009;212:685-92.

23. Goen T, Dobler L, Koschorreck J, Muller J, Wiesmuller GA, Drexler H, et al. Trends of the internal phthalate exposure of young adults in Germany - follow-up of a retrospective human biomonitoring study. Int J Hyg Environ Health. 2011;215:36-45.

24. Koch HM, Becker K, Wittassek M, Seiwert M, Angerer J, KolossaGehring M. Di-n-butylphthalate and butylbenzylphthalate-urinary metabolite levels and estimated daily intakes: pilot study for the German Environmental Survey on children. J Exp Sci Environ Epidemiol. 2007;17:378-87.

25. Koch HM, Kolossa-Gehring M, Schroter-Kermani C, Angerer J, Bruning T. Bisphenol A in $24 \mathrm{~h}$ urine and plasma samples of the German Environmental Specimen Bank from 1995 to 2009: a retrospective exposure evaluation. J Expo Sci Environ Epidemiol. 2012;22:610-6.

26. Schulz C, Conrad A, Becker K, Kolossa-Gehring M, Seiwert M, Seifert B. Twenty years of the German Environmental Survey (GerES): human biomonitoring-temporal and spatial (West Germany/East Germany) differences in population exposure. Int $\mathrm{J}$ Hyg Environ Health. 2007;210:271-97.

27. Schutze A, Kolossa-Gehring M, Apel P, Bruning T, Koch HM. Entering markets and bodies: increasing levels of the novel plasticizer Hexamoll (R) DINCH (R) in $24 \mathrm{~h}$ urine samples from the German Environmental Specimen Bank. Int J Hyg Environ Health. 2014;217:421-6. First report addressing exposure to DINCH, a phthalate replacement, in Germany.

28. Wittassek M, Wiesmuller GA, Koch HM, Eckard R, Dobler L, Muller J, et al. Internal phthalate exposure over the last two decades - a retrospective human biomonitoring study. Int J Hyg Environ Health. 2007;210:319-33.

29. Wittassek M, Koch HM, Angerer J, Bruning T. Assessing exposure to phthalates - the human biomonitoring approach. Mol Nutr Food Res. 2011;55:7-31.

30. Health Canada. Second report on human biomonitoring of environmental chemicals in Canada: results of the Canadian Health Measures Survey Cycle 2 (2009-2011). Ottawa, Ontario, Canada: Health Canada. 2013. Available: http://www.hc-sc.gc.ca/ewh-semt/ pubs/contaminants/chms-ecms-cycle2/index-eng.php [accessed 201517 Mar]

31. Haines DA, Murray J. Human biomonitoring of environmental chemicals - early results of the 2007-2009 Canadian Health Measures Survey for males and females. Int J Hyg Environ Health. 2012;215:133-7.

32. CPSC. Chronic Hazard Advisory Panel on Phthalates and Phthalates Alternatives. Bethesda, MD 20814:U.S. Consumer Product Safety Commission. Directorate for Health Sciences. 2014. Available: http://www.cpsc.gov//PageFiles/169902/CHAPREPORT-With-Appendices.pdf [accessed $201512 \mathrm{Mar}$.

33. ATSDR. Toxicological profile for di(2-ethylhexyl)phthalate (DEHP). Atlanta, GA: Agency for Toxic Substances and Disease Registry. 2002. Available: http://www.atsdr.cdc.gov/ToxProfiles/ tp.asp?id=684\&tid $=65$ [accessed $201526 \mathrm{Mar}$.

34. Kavlock R, Barr D, Boekelheide K, Breslin W, Breysse P, Chapin $R$, et al. NTP-CERHR Expert Panel update on the reproductive and developmental toxicity of di(2-ethylhexyl) phthalate. Reprod Toxicol. 2006;22:291-399.

35. ATSDR. Toxicological profile for di-n-butyl phthalate (DBP). Atlanta, GA: Agency for Toxic Substances and Disease Registry. 2001. Available: http://www.atsdr.cdc.gov/ToxProfiles/tp.asp?id= 859\&tid=167 [accessed $201526 \mathrm{Mar}$.

36. Gallinger ZR, Nguyen GC. Presence of phthalates in gastrointestinal medications: is there a hidden danger? World J Gastroenterol. 2013;19:7042-7.

37. Hernandez-Diaz S, Su YC, Mitchell AA, Kelley KE, Calafat AM, Hauser R. Medications as a potential source of exposure to phthalates among women of childbearing age. Reprod Toxicol. 2013;37:1-5.

38. Kavlock R, Boekelheide K, Chapin R, Cunningham M, Faustman E, Foster P, et al. NTP Center for the Evaluation of Risks to Human 
Reproduction: phthalates expert panel report on the reproductive and developmental toxicity of di-n-butyl phthalate. Reprod Toxicol. 2002;16:489-527.

39. Kelley KE, Hernandez-Diaz S, Chaplin EL, Hauser R, Mitchell AA. Identification of phthalates in medications and dietary supplement formulations in the United States and Canada. Environ Health Perspect. 2012;120:379-84

40. Hernandez-Diaz S, Mitchell AA, Kelley KE, Calafat AM, Hauser R. Medications as a potential source of exposure to phthalates in the US population. Environ Health Perspect. 2009;117:185-9.

41. Seckin E, Fromme H, Volkel W. Determination of total and free mono-n-butyl phthalate in human urine samples after medication of a di-n-butyl phthalate containing capsule. Toxicol Lett. 2009;188: 33-7.

42. Koch HM, Muller J, Drexler H, Angerer J. Dibutylphthalate (DBP) in medications: are pregnant women and infants at risk? Umweltmed Forsch Prax. 2005;10:144-6.

43. Hauser R, Duty S, Godfrey-Bailey L, Calafat AM. Medications as a source of human exposure to phthalates. Environ Health Perspect. 2004;112:751-3. This paper described for the first time that medications can be a source of exposure to certain phthalates.

44. Ha M, Kwon HJ, Leem JH, Kim HC, Lee KJ, Park I, et al. Korean Environmental Health Survey in Children and Adolescents (KorEHS-C): survey design and pilot study results on selected exposure biomarkers. Int J Hyg Environ Health. 2014;217:260-70.

45. de Renzy-Martin KT, Frederiksen H, Christensen JS, Kyhl HB, Andersson AM, Husby S, et al. Current exposure of 200 pregnant Danish women to phthalates, parabens and phenols. Reproduction. 2014;147:443-53.

46. Dewalque L, Pirard C, Charlier C. Measurement of urinary biomarkers of parabens, benzophenone-3, and phthalates in a Belgian population. Biomed Res Int. 2014. 2014: 649314. Published online 2014 February 25. doi: 10.1155/2014/649314.

47. Kasper-Sonnenberg M, Koch HM, Wittsiepe J, Bruning T, Wilhelm M. Phthalate metabolites and bisphenol A in urines from German school-aged children: results of the Duisburg Birth Cohort and Bochum Cohort Studies. Int J Hyg Environ Health. 2014;217: 830-8.

48. Lioy PJ, Gennings C, Hauser R, Koch HM, Kortenkamp A. Changing trends in phthalate exposures. Environ Health Perspect. 2014; 122:A264.

49. Polanska K, Ligocka D, Sobala W, Hanke W. Phthalate exposure and child development: the Polish Mother and Child Cohort Study. Early Hum Dev. 2014;90:477-85.

50. Berman T, Goldsmith R, Goen T, Spungen J, Novack L, Levine H, et al. Urinary concentrations of environmental contaminants and phytoestrogens in adults in Israel. Environ Int. 2013;59:478-84.

51. Kay VR, Bloom MS, Foster WG. Reproductive and developmental effects of phthalate diesters in males. Crit Rev Toxicol. 2014;44: 467-98.

52. Martino-Andrade AJ, Chahoud I. Reproductive toxicity of phthalate esters. Mol Nutr Food Res. 2010;54:148-57.

53. Lyche JL, Gutleb AC, Bergman A, Eriksen GS, Murk AJ, Ropstad E, et al. Reproductive and developmental toxicity of phthalates. J Toxicol Environ Health Part B. 2009;12:225-49.

54. Kay VR, Chambers C, Foster WG. Reproductive and developmental effects of phthalate diesters in females. Crit Rev Toxicol. 2013;43:200-19.

55. Martinez-Arguelles DB, Campioli E, Culty M, Zirkin BR, Papadopoulos V. Fetal origin of endocrine dysfunction in the adult: the phthalate model. J Steroid Biochem Mol Biol. 2013;137:5-17.

56. Hauser R. Urinary phthalate metabolites and semen quality: a review of a potential biomarker of susceptibility. Int J Androl. 2008;31:112-6.
57. Matsumoto M, Hirata-Koizumi M, Ema M. Potential adverse effects of phthalic acid esters on human health: a review of recent studies on reproduction. Regul Toxicol Pharmacol. 2008;50:37-49.

58. Heudorf U, Mersch-Sundermann V, Angerer E. Phthalates: toxicology and exposure. Int J Hyg Environ Health. 2007;210:623-34.

59. European Union. Directive 2005/84/EC of the European Parliament and of the Council of 14 December 2005 amending for the 22nd time Council Directive 76/769/EEC on the approximation of the laws, regulations and administrative provisions of the Member States relating to restrictions on the marketing and use of certain dangerous substances and preparations (phthalates in toys and childcare articles). Council, European Parliament. 2005. Available: http://eur-lex.europa.eu/legal-content/EN/TXT/PDF/? uri=CELEX:32005L0084\& from=EN [accessed 20159 Apr].

60. Health Canada. Industry guide to health Canada's safety requirements for children's toys and related products, 2012. Ottawa, Ontario: Health Canada. 2012. Available: http://www.hc-sc.gc.ca/ cps-spc/alt_formats/pdf/pubs/indust/toys-jouets/toys-jouets-eng. pdf [accessed $201512 \mathrm{Apr}$ ].

61. CPSC. Consumer Product Safety Improvement Act of 2008. Washington, DC: Consumer Product Safety Commission. 2008. Available: http://www.cpsc.gov/en/Regulations-Laws-Standards/ Statutes/The-Consumer-Product-Safety-Improvement-Act/ [accessed 201517 Mar].

62. CPSC. Prohibition of children's toys and child care articles containing specified phthalates. Fed Regist. 2014;79:78324-43.

63. Dooley EE. Phthalate levels decreasing in beauty products. Environ Health Perspect. 2009;117:A19.

64. Kessler R. More than cosmetic changes: taking stock of personal care product safety. Environ Health Perspect. 2015;123:A120-7.

Report describing changes in manufacturing and marketing practices of personal care products prompted by public concerns regarding the safety of certain personal care products ingredients.

65. Silva MJ, Jia T, Samandar E, Preau JL, Calafat AM. Environmental exposure to the plasticizer 1,2-cyclohexane dicarboxylic acid, diisononyl ester (DINCH) in US adults (2000-2012). Environ Res. 2013;126:159-63. First report addressing exposure to DINCH, a phthalate replacement, in the United States.

66. Koch HM, Wittassek M, Bruning T, Angerer J, Heudorf U. Exposure to phthalates in 5-6 years old primary school starters in Germany - a human biomonitoring study and a cumulative risk assessment. Int J Hyg Environ Health. 2011;214:188-95.

67. European Union. EU Risk Assessment report- BPA. European Union. 2003. Available: http://oehha.ca.gov/prop65/crnr notices/ state_listing/data_callin/pdf/EU_bisphenolareport325.pdf [accessed 201212 Aug].

68. National Toxicology Program. NTP brief on bisphenol A [CAS NO. 80-05-07]. 2008. Available: http://ntp.niehs.nih.gov/ntp/ohat/ bisphenol/bisphenol.pdf [accessed $20152 \mathrm{Mar}$ ].

69. Arbuckle TE, Davis K, Marro L, Fisher M, Legrand M, LeBlanc A, et al. Phthalate and bisphenol A exposure among pregnant women in Canada - results from the MIREC study. Environ Int. 2014;68: 55-65.

70. Berman T, Goldsmith R, Goen T, Spungen J, Novack L, Levine H, et al. Urinary concentrations of environmental contaminants and phytoestrogens in adults in Israel. Environ Int. 2013;59:478-84.

71. Casas M, Valvi D, Luque N, Ballesteros-Gomez A, Carsin AE, Fernandez MF, et al. Dietary and sociodemographic determinants of bisphenol A urine concentrations in pregnant women and children. Environ Int. 2013;56:10-8.

72. Frederiksen H, Jensen TK, Jorgensen N, Kyhl HB, Husby S, Skakkebk NE, et al. Human urinary excretion of non-persistent environmental chemicals: an overview of Danish data collected between 2006 and 2012. Reproduction. 2014;147:555-65. 
73. Mortensen ME, Calafat AM, Ye XY, Wong LY, Wright DJ, Pirkle $\mathrm{JL}$, et al. Urinary concentrations of environmental phenols in pregnant women in a pilot study of the National Children's Study. Environ Res. 2014;129:32-8.

74. Kim K, Park H, Yang W, Lee JH. Urinary concentrations of bisphenol $\mathrm{A}$ and triclosan and associations with demographic factors in the Korean population. Environ Res. 2011;111:1280-5.

75. Bushnik T, Haines D, Levallois P, Levesque J, Van Oostdam J, Viau C. Lead and bisphenol A concentrations in the Canadian population. Health Reports. 2010;21.

76. Wang B, Wang HX, Zhou W, He YH, Zhou Y, Chen Y, et al. Exposure to bisphenol A among school children in eastern China: a multicenter cross-sectional study. J Expo Sci Environ Epidemiol. 2014;24:657-64.

77. Ye XB, Pierik FH, Hauser R, Duty S, Angerer J, Park MM, et al. Urinary metabolite concentrations of organophosphorous pesticides, bisphenol $\mathrm{A}$, and phthalates among pregnant women in Rotterdam, the Netherlands: the Generation R study. Environ Res. 2008;108:260-7.

78. Calafat AM, Kuklenyik Z, Reidy JA, Caudill SP, Ekong J, Needham LL. Urinary concentrations of bisphenol A and 4nonyl phenol in a human reference population. Environ Health Perspect. 2005;113:391-5.

79. EFSA. Scientific Opinion on the risks to public health related to the presence of bisphenol A (BPA) in foodstuffs. EFSA (European Food Safety Authority). 2015. Available: http://www.efsa.europa.eu/en/efsajournal/pub/3978.htm [accessed 20159 Apr].

80. Health Canada. Health Canada's Updated Assessment of Bisphenol A (BPA) Exposure from Food Sources. 2012. Available: http:// www.hc-sc.gc.ca/fn-an/securit/packag-emball/bpa/bpa_hra-ers2012-09-eng.php\#a3 [accessed $201522 \mathrm{Mar}$ ].

81. FDA. Bisphenol A (BPA): use in food contact application. U.S. Food and Drug Administration. 2014. Available: http://www.fda.
gov/NewsEvents/PublicHealthFocus/ucm064437.htm [accessed 201516 Mar].

82. Ritter SK. Bisphenol A. Chemical \& Engineering News. 2011;89: 13. Available: https://pubs.acs.org/cen/coverstory/89/8923cover. html [accessed 201516 Apr].

83. Bittner GD, Yang CZ, Stoner MA. Estrogenic chemicals often leach from BPA-free plastic products that are replacements for BPAcontaining polycarbonate products. Environ Health. 2014;13:4154.

84. Kitamura S, Suzuki T, Sanoh S, Kohta R, Jinno N, Sugihara $\mathrm{K}$, et al. Comparative study of the endocrine-disrupting activity of bisphenol A and 19 related compounds. Toxicol Sci. 2005;84:249-59.

85. Ye X, Zhou X, Kramer J, Calafat AM. Do human exposures to bisphenol A and three other bisphenol analogs track market changes? Environ Health Perspect. 2014-Abstracts of the 2014 Conference of the International Society of Environmental Epidemiology (ISEE), August 24-8, 2014, Seattle, WA. 2014. Environ Health Perspect; http://ehp.niehs.nih.gov/isee/p1-001/. Abstract Number: 1527 | ID : P1-001.

86. USEPA. Pesticides industry sales and usage -2006 and 2007 market estimates. Washington, DC:U.S. Environmental Protection Agency. 2011. Available: http://www.epa.gov/pesticides/pestsales/ 07pestsales/market estimates2007.pdf [accessed 201517 Apr].

87. USEPA. Revised human health risk assessment on chlorpyrifos. 2014. Available: http://www2.epa.gov/ingredients-usedpesticide-products/revised-human-health-risk-assessmentchlorpyrifos [accessed 201515 Apr].

88. USEPA. Pyrethroids and pyrethrins. 2014. Available: http://www. epa.gov/oppsrrd1/reevaluation/pyrethroids-pyrethrins.html [accessed $201515 \mathrm{Apr}$.

89. Becker K, Seiwert M, Angerer J, Kolossa-Gehring M, Hoppe HW, Ball M, et al. GerES IV pilot study: assessment of the exposure of German children to organophosphorus and pyrethroid pesticides. Int J Hyg Environ Health. 2006;209:221-33. 